\title{
Canções sem palavras, de Felix Mendelssohn: um experimento escritural multiartístico ${ }^{1}$
}

Marcus Mota*

Entre 1829 e 1843, Felix Mendelssohn (1809-1847) elaborou o ciclo de obras para piano intitulado Canções sem palavras (Lieder ohne Worte) ${ }^{2}$. Este ciclo, que logo foi incorporado ao repertório pianístico, atravessa a vida e carreira de Mendelssohn, formando, como as sonatas de Beethoven, um diário artístico do compositor ${ }^{3}$. Além do repertório pianístico, o ciclo foi ponto de partida para, entre outros processos criativos que exploram as tensões entre artes em contato, como o Romances sans paroles (1874), de Paul Verlaine (1844-1896). Assim, constitui-se uma longa tradição de produções estéticas e reflexões artísticas que explora as fronteiras entre texto, som e imagem, a qual irrompe como horizonte hermenêutico para estudos sobre os nexos entre tradução e musicalidade.

\footnotetext{
${ }^{1}$ Este texto é parte integrante de pesquisa de pós-doutoramento sobre Artes em Contato, com supervisão de Mário Vieira de Carvalho (CESEM-NOVA) e Maria João Brilhante (CET-FLUL), ambas instituições sediadas em Lisboa. Este projeto de Pesquisa foi financiado pela FAP-DF.

* Universidade de Brasília (UnB).

${ }^{2}$ A primeira coleção de peças, publicada na Inglaterra em 1832, tinha por título Original Melodies for the Piano-Forte (Melodias originais para piano). Em Paris, a primeira coleção foi publicada no mesmo ano com o título de Six Romances sans Paroles (Seis Romanzas sem palavras). No ano seguinte, em Bonn, é que o título Lieder ohne Worte se estabelece. V. JONES, 1992, p. 241-245; TODD, 2003, p. 262-263.

${ }^{3}$ No julgamento de R. Larry Todd, “[e]laboradas inicialmente para música doméstica de amadores, essas peças populares de piano ressoaram nas respeitosas mansões de classe média pela Europa, nas quais o piano adquiria a posição de instrumento mais preferido (TODD, 2004, p. 192)"
} 
A novidade do ciclo elaborado por Mendelssohn e seu impacto advêm de uma estratégica ambiguidade, pois a canção de câmara (Lied) é aqui absorvida em uma diversa configuração: no lugar da interação entre um cantor e o piano, entre as palavras cantadas e os sons do piano, temos apenas música instrumental. Esta definição negativa das Canções sem palavras rompe com as expectativas de um gênero performativo, provocando a justaposição entre aquilo que se conhece (o Lied) e aquilo que se passa a conhecer (música instrumental em forma de Lied).

Essa ambiguidade foi respondida de diversas maneiras. A irmã de Mendelssohn, Fanny Hensel, também pianista e compositora, afirma em 1838 em carta ao irmão:

\footnotetext{
Querido Felix, quando as palavras são removidas das canções (Singliedern), como estavam fazendo nas peças para concerto, isso é o equivalente do experimento de adicionar palavras para tuas canções instrumentais, a outra metade de um mundo revirado. (CITRON, 1987, p. 547, tradução nossa) ${ }^{4}$
}

Esse mundo às avessas, verkehrten Welt, como o olhar de Alice através do espelho, encontra-se, pois, como uma possibilidade dentro da tradição dominante do Lied. Na percepção de Fanny Hensel, a correlação entre a prática contemporânea de arranjos instrumentais para canções folclóricas estaria em oposição complementar ao se criar letras para as canções sem palavras para piano do irmão. Teríamos um sistema de relações:

\footnotetext{
${ }^{4}$ Original em alemão: Lieber Felix, wenn Singliedern die Worte weggenommen werden, um sie als Concertstück zu brauchen, so ist das ein richtiges Gegenstück zu dem Experiment, Deinen Spielliedern Worte unterzulegen, die andre Hailfte von der verkehrten Welt.
} 


\section{Gráfico 1: Modos de relações entre práticas e mídias}

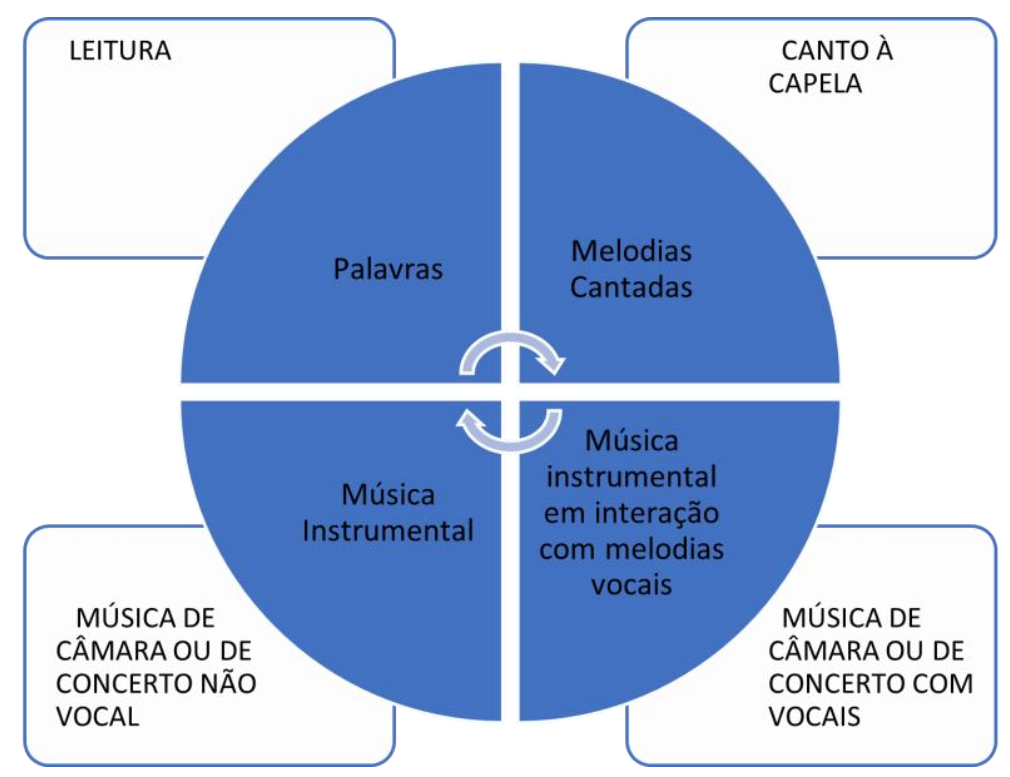

Fonte: LADI-UnB

Paradoxalmente, mesmo o experimento de Mendelssohn se efetivando como música instrumental não vocal, isso não impediu que as peças de Canções sem palavras fossem recebidas como canções com letras. Em 1835, Robert Schumann, que comporia um ano depois a sonata para piano denominada Konzert ohne Orchester (Concerto sem Orquestra) ao comentar a segunda coleção dos experimentos de Mendelssohn, comenta:

Quem de nós na hora no crepúsculo não se sentou a seu piano de armário e no meio da improvisação inconscientemente começou a cantar uma melodia silenciosa? Se alguém conseguir tocar a melodia com o acompanhamento, e se esse alguém for um Mendelssohn, as mais belas 'Canções sem palavras' serão produzidas. Ou ainda mais fácil: compor a partir de um texto, eliminar as palavras, entregando [a obra] para o mundo. (tradução nossa) $)^{5}$

\footnotetext{
${ }^{5}$ Original em alemão: Wer hätte nicht einmal in der Dämmerungsstunde am Clavier gesessen (...) und mitten im Phantasieren unbewußt eine leise Melodie dazu gesungen? Kann man nun zufaillig die
} 
Figura 1: Original do Comentário de Robert Schumann

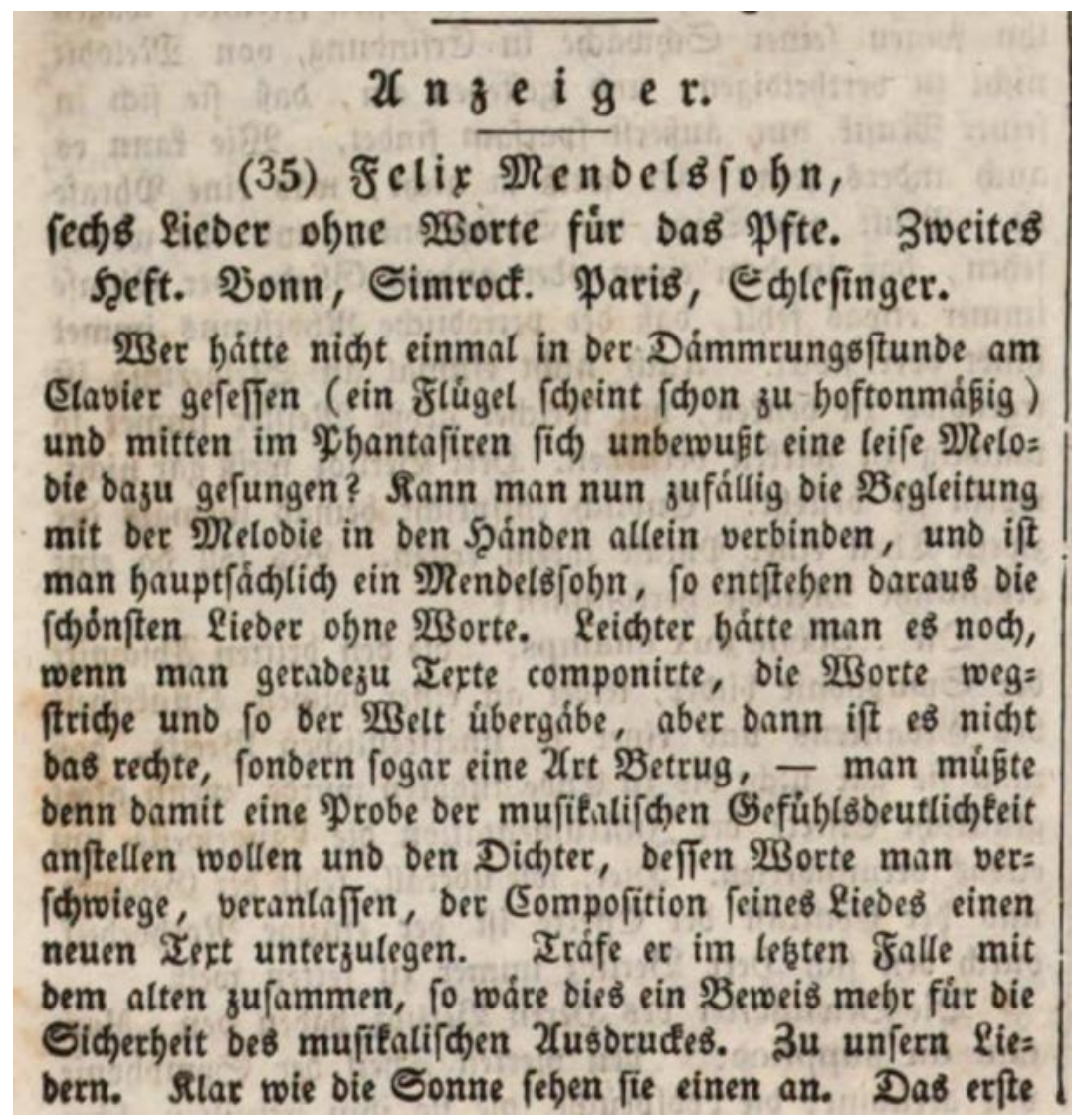

Fonte: Neue Zeitschrift für Musik, 50, jun 1935, n. 35.

Schumann clarifica a situação do compositor, seus métodos de trabalho. A interação entre o músico e seu instrumento em situação de composição-em-performance ou improvisação promove uma experiência dialógica, em que o material melódico do piano se desdobra no material

Begleitung mit der Melodie in den Händen allein verbinden, und ist man hauptsächlich ein Mendelssohn, so entstehen daraus die schönsten Lieder ohne Worte. Leichter hätte man es noch, wenn man geradezu Texte komponirte, die Worte wegstriche und so der Welt übergabe. 
vocal do performer. A cena descrita por Schumann é um topos líricodramático: atos, cenário e pathos. Aqui Schumann define a poética presente na obra Canções sem palavras: vozes, linhas melódicas como traduções musicais de uma contextura de atos dialógicos.

Schumann avança em sua fenomenologia: outra maneira é homóloga ao cancionista, que tem seu ponto de partida em um texto para o musicar. Mas no lugar da correspondência entre palavra e música, a melodia vocal com texto, excluem-se as palavras. Em um e outro caso, embora tenhamos métodos de composição diversos, há uma nova relação com a palavra, com o texto. No primeiro caso, a improvisação em voz baixa do pianista traduz a situação em volta, sua audiovisualidade. Aquilo que é percebido, imaginado, não é verbalizado linguisticamente, embora existam palavras para sua concretização. No segundo, o texto como pretexto é analisado, decomposto e rematerializado em uma ordem de sons. Da virtualidade mental a uma esquematização em roteiro, as palavras ou o texto verbal deixam de constituir o primeiro plano das cenas dramático-musicais. Mas continua a haver trocas, interações, diálogos, uma sucessão de acontecimentos e respostas emocionais. A transmutação da palavra em cena é um descentramento de atos verbais como unificadores de uma experiência multissensorial. E é a música que proporciona essa abertura, não por fechar em si mesma, mas por organizar-se dramaturgicamente, como um livro do mundo, como já veremos.

Esse novo papel das relações entre palavra e música é atestado pelo próprio Mendelssohn. Respondendo às inúmeras tentativas de reduzir as experiências multissensoriais de Canções sem palavras a explicações verbais, Mendelssohn escreveu em 15-10-1842: 
Fala-se tanto de música mas pouco é dito. Acredito que as palavras não são suficientes, e, se eu acreditasse que elas são suficientes, ao fim pararia de fazer mais música. (...) Se você me perguntar sobre o que eu pensava quando compunha, respondo: apenas a canção como está. E se eu tivesse determinadas palavras em mente para uma e outra dessas canções, nunca as diria para quem quer que fosse, pois as mesmas palavras significam coisas diferentes para diferentes pessoas, apenas a canção pode dizer a mesma coisa, despertar os mesmos sentimentos em uma pessoa e outra, sentimento que, no entanto, não é expresso pelas mesmas palavras. (MENDELSSOHN, 1865, p. 337-338, tradução nossa) ${ }^{6}$

O texto supracitado é trecho de carta a Marc André Souchay (17961868), primo da esposa de Mendelssohn, que buscava soluções verbais definitivas paras as Canções sem palavras. Na carta que provocou a resposta do compositor, Souchay atribui um conceito, imagem ou emoção para cada uma das peças do ciclo 7 . De fato, até a época da troca dessa troca de cartas, das 24 músicas analisadas por Souchay, Mendelssohn havia dado um título, como uma legenda de quadro, a apenas quatro peças - Venetianisches Gondellied (Canção do Gondoleiro Veneziano) Op. 19 n. 6 e Op.30 n. 6, Duetto (Dueto) Op. 38 n. 6, e o Volkslied (Canção do Povo/Tradicional), Op. 53 n. $5^{8}$. Mesmo em seu esforço em delimitar semanticamente a referência dominante de cada canção, como que provendo sua chave hermenêutica, Souchay deixa sem designação 5 das 24 músicas que tentou explicar.

Nesse sentido, a resposta de Mendelssohn precisa ser compreendida no contexto da recusa do tipo de empreendimento intelectual proposto por

\footnotetext{
${ }^{6}$ Original em alemão: Es wird so viel uiber Musik gesprochen, und so wenig gesagt. Ich glaube uiberhaupt die Worte reichen nicht hin dazu, und fände ich, dass sie hinreichten, so würde ich am Ende gar keine Musik mehr machen. (...) Fragen Sie mich, was ich mir dabei gedacht habe, so sage ich: gerade das Lied wie es dasteht. Und habe ich bei dem einen oder andern ein bestimmtes Wort oder bestimmte Worte im Sinn gehabt, so mag ich die doch keinem Menschen aussprechen, weil das Wort dem Einen nicht heißt, was es dem Andern heißt, weil nur das Lied dem Einen dasselbe sagen kann, dasselbe Gefuhl in ihm erwecken kann, wie im Andern - ein Gefuihl, das sich aber nicht durch dieselben Worte ausspricht. ${ }^{7}$ V. tabela com todos os rótulos propostos por Souchay em TODD, 2012, p. 204.

${ }^{8}$ Para as obras, sigo edição Henle (MENDELSSOHN, 2006). Para um comentário detalhado da história da edição do ciclo, v. JOST 1988.
} 
Souchay. Ao defender a insuficiência ou inadequação da verbalização para determinar a complexidade da cena multissensorial provocada pelas canções sem palavras, Mendelssohn se comprime no exíguo espaço de oposição absoluta entre linguagem e música. A atribuição de um rótulo linguístico para nomear e sintetizar a amplitude da experiência multidimensional, seja no início do processo criativo seja no produto organizado ao fim - é contra isso que Mendelssohn se posiciona. E aquilo que está escrito na partitura, embora possa conter gestos identificáveis como os de uma caça em Op. 19, n. 3. , na totalidade da experiência sonora e imaginativa da peça não se reduz ao reconhecimento dos referentes.

É a partir daí que se pode argumentar sobre a decisiva contribuição de Mendelssohn para a discussão de composições multissensoriais. Pois no lugar de substituir a centralidade da linguagem pela centralidade da música, as ideias de Mendelssohn e a poética de Canções sem Palavras nos conduzem para outra direção. E a pista na canção mesma, gerade das Lied wie es dasteht, naquilo que especificamente o seu modo de organização de materiais sonoros possibilita.

Para ir além de falácia lógica da circularidade, torna-se crucial interrogar a própria obra de Mendelssohn. Canções sem Palavras se articula em oito livros, cada um com seis peças instrumentais para piano, constituindo um total de 48 obras. Em um primeiro momento, essa macroestrutura deliberadamente assume o lugar de uma superssimetria9: todos os livros exibem o mesmo número, a mesma proporção. Na tabela abaixo, essa superssimetria é explicitada ${ }^{10}$ :

\footnotetext{
${ }^{9}$ RATNER 1992.

10 Há outras tabelas, como https://www.rolf-musicblog.net/mendelssohn-diary-2015-10-26/\#swow . Acesso em 20 mar 2020. E em PHILLLIPS, 2007, p. 105.
} 
Tabela 1: Descrição dos livros de Canções sem palavras.

\begin{tabular}{|c|c|c|c|}
\hline IDENTIFICAÇÃO & $\begin{array}{l}\text { ANDAMENTO/ } \\
\text { TONALIDADE }\end{array}$ & DURAÇÃO & TÍTULO 11 \\
\hline $\begin{array}{l}1.1(1829-1830) \\
\text { Opus } 19 .\end{array}$ & $\begin{array}{l}\text { Andante con moto } \\
\text { E Maior }\end{array}$ & $3: 32$ & \{Resignação/Doces recordações $\}$ \\
\hline 1.2 & $\begin{array}{l}\text { Andante } \\
\text { expressivo } \\
\text { A menor }\end{array}$ & $2: 28$ & $\{$ Melancolia/ Arrependimentos $\}$ \\
\hline 1.3 & $\begin{array}{l}\text { Molto allegro e } \\
\text { vivace } \\
\text { A Maior }\end{array}$ & $2: 20$ & $\begin{array}{l}\text { \{Cenas de uma Caçada/ } \\
\text { Jägerlied (Canção de Caça), A } \\
\text { caça\} }\end{array}$ \\
\hline 1.4 & $\begin{array}{l}\text { Moderato } \\
\text { A Maior }\end{array}$ & $1: 51$ & $\begin{array}{l}\text { \{Louvor à bondade de Deus/ } \\
\text { Confiança }\}\end{array}$ \\
\hline 1.5 & $\begin{array}{l}\text { Poco agitato } \\
\text { F\# menor }\end{array}$ & $3: 06$ & $\{$-------/ Agitação\} \\
\hline 1.6 & $\begin{array}{l}\text { Andante sostenuto } \\
\text { G menor }\end{array}$ & $2: 14$ & $\begin{array}{l}\text { Venetianisches Gondellied } \\
\text { (Canção do Gondoleiro } \\
\text { Veneziano) }\end{array}$ \\
\hline $\begin{array}{l}2.1(1833-1834) \\
\text { Opus } 30 .\end{array}$ & $\begin{array}{l}\text { Andante } \\
\text { espressivo } \\
\text { Eb Maior }\end{array}$ & $3: 58$ & $\begin{array}{l}\text { Representação de um } \\
\text { semblante devoto e } \\
\text { agradecido/ Contemplação }\end{array}$ \\
\hline 2.2 & $\begin{array}{l}\text { Allegro di molto } \\
\text { Bb menor }\end{array}$ & 2:00 & \{Cena de caça/Problema\} \\
\hline 2.3 & $\begin{array}{l}\text { Adagio non } \\
\text { troppo } \\
\text { E Maior }\end{array}$ & $1: 53$ & \{-------/Consolação\} \\
\hline
\end{tabular}

11 Em chaves são assinalados, em ordem, os atributos propostos por Souchay e pela tradição interpretativa, quando for o caso. E, em negrito, marcam-se os títulos que Mendelssohn indicou na publicação de suas obras. 


\begin{tabular}{|c|c|c|c|}
\hline 2.4 & $\begin{array}{l}\text { Agitato e con } \\
\text { fuoco B menor }\end{array}$ & 2:46 & $\begin{array}{l}\{\text { Forte desejo de ir para o } \\
\text { mundo/O vagabundo }\}\end{array}$ \\
\hline 2.5 & $\begin{array}{l}\text { Andante grazioso } \\
\text { D major }\end{array}$ & $2: 13$ & \{Canção de ninar/O Córrego\} \\
\hline 2.6 & $\begin{array}{l}\text { Allegretto } \\
\text { tranquillo } \\
\text { F\# menor }\end{array}$ & $3: 07$ & Venetianisches Gondellied \\
\hline $\begin{array}{l}\text { 3.1(1836-1837) } \\
\text { Opus } 38\end{array}$ & $\begin{array}{l}\text { Con moto } \\
\text { Eb Maior }\end{array}$ & $2: 29$ & $\begin{array}{l}\text { \{Amor sem limites, mas não } \\
\text { correspondido/ Estrela da } \\
\text { noite\} }\end{array}$ \\
\hline 3.2 & $\begin{array}{l}\text { Allegro non } \\
\text { troppo } \\
\text { C menor }\end{array}$ & $1: 59$ & $\begin{array}{l}\text { \{Forte expectativa, alternando } \\
\text { saudade, ansiedade e dor/ } \\
\text { Felicidade perdida }\}\end{array}$ \\
\hline 3.3 & $\begin{array}{l}\text { Presto e molto } \\
\text { vivace } \\
\text { E Maior }\end{array}$ & $2: 17$ & $\begin{array}{l}\text { \{Canção de amor/A harpa do } \\
\text { poeta\} }\end{array}$ \\
\hline 3.4 & $\begin{array}{l}\text { Andante } \\
\text { A Maior }\end{array}$ & $2: 10$ & $\{$ Contentamento/Esperança\} \\
\hline 3.5 & $\begin{array}{l}\text { Agitato } \\
\text { A menor }\end{array}$ & $2: 21$ & $\{$ Desespero/apassionata\} \\
\hline 3.6 & $\begin{array}{l}\text { Andante con moto } \\
\text { Ab Maior }\end{array}$ & $2: 47$ & Duetto \\
\hline
\end{tabular}




\begin{tabular}{|c|c|c|c|}
\hline $\begin{array}{l}4.1(1839-1841) \\
\text { Opus } 53\end{array}$ & $\begin{array}{l}\text { Andante con moto } \\
\text { Ab Maior }\end{array}$ & 3:03 & $\{-----/ \mathrm{Na}$ enseada $\}$ \\
\hline 4.2 & $\begin{array}{l}\text { Allegro non } \\
\text { troppo } \\
\text { Eb Maior }\end{array}$ & $2: 32$ & \{Anseio/ Nuvens escamosas\} \\
\hline 4.3 & $\begin{array}{l}\text { Presto agitato } \\
\text { G menor }\end{array}$ & $2: 31$ & \{Desespero/ Agitação \\
\hline 4.4 & $\begin{array}{l}\text { Adagio } \\
\text { F Maior }\end{array}$ & $2: 15$ & $\begin{array}{l}\{-----/ \text { Tristeza da alma, } \\
\left.\text { Abendlied, (Canção da noite }{ }^{12}\right\}\end{array}$ \\
\hline 4.5 & $\begin{array}{l}\text { Allegro con fuoco } \\
\text { A menor }\end{array}$ & $2: 47$ & $\begin{array}{l}\text { Volkslied }^{13} \text { (Canção do povo, } \\
\text { tradicional) }\end{array}$ \\
\hline 4.6 & $\begin{array}{l}\text { Molto allegro } \\
\text { vivace } \\
\text { A Maior }\end{array}$ & $2: 22$ & $\{-----/ O$ Vôo $\}$ \\
\hline $\begin{array}{l}5.1(1842-1844) \\
\text { Opus } 62\end{array}$ & $\begin{array}{l}\text { Andante } \\
\text { espressivo } \\
\text { G Maior }\end{array}$ & $2: 10$ & $\{$ Brisa de Maio\} \\
\hline 5.2 & $\begin{array}{l}\text { Allegro con fuoco } \\
\text { B b Maior }\end{array}$ & $1: 46$ & $\{\mathrm{O}$ Começo $\}$ \\
\hline 5.3 & $\begin{array}{l}\text { Andante } \\
\text { maestoso }^{14} \\
\text { E menor }\end{array}$ & $2: 28$ & $\begin{array}{l}\{\text { Trauermarsch, (Marcha } \\
\text { Fúnebre)\} }\end{array}$ \\
\hline 5.4 & $\begin{array}{l}\text { Allegro con anima } \\
\text { G Maior }\end{array}$ & $1: 18$ & \{Música da Manhã $\}$ \\
\hline
\end{tabular}

\footnotetext{
${ }^{12}$ Nome presente em alguns autógrafos de Mendelssohn, segundo TODD, 1979. p. 245.

${ }^{13}$ Souchay atribui à canção "Canção guerreira folclórica".

14 Tema associado a ocasião de uma marcha fúnebre. Orquestrada por Ignaz Moscheles, foi apresentada durante o funeral de Mendelssohn.
} 


\begin{tabular}{|c|c|c|c|}
\hline 5.5 & $\begin{array}{l}\text { Andante con moto } \\
\text { A menor }\end{array}$ & $2: 43$ & Venetianisches Gondellied \\
\hline 5.6 & $\begin{array}{l}\text { Allegretto } \\
\text { grazioso } \\
\text { A Maior }\end{array}$ & $2: 24$ & $\begin{array}{l}\left\{\text { Frühlingslied }{ }^{15},(\text { Canção da }\right. \\
\text { Primavera })\}\end{array}$ \\
\hline $\begin{array}{l}6.1(1843-1845) \\
\text { Opus } 67\end{array}$ & $\begin{array}{l}\text { Andante } \\
\text { Eb Maior }\end{array}$ & $2: 29$ & $\{$ Meditação\} \\
\hline 6.2 & $\begin{array}{l}\text { Allegro leggiero } \\
\text { F\# menor }\end{array}$ & 3:00 & \{Ilusões Perdidas\} \\
\hline 6.3 & $\begin{array}{l}\text { Andante } \\
\text { tranquillo } \\
\text { Bb Maior }\end{array}$ & $2: 42$ & \{Cântico dos Peregrinos\} \\
\hline 6.4 & $\begin{array}{l}\text { Presto } \\
\text { C Maior }\end{array}$ & $1: 46$ & $\begin{array}{l}\{\text { Spinnerlied (Canção da } \\
\left.\text { girada) }{ }^{16}\right\}\end{array}$ \\
\hline 6.5 & $\begin{array}{l}\text { Moderato } \\
\text { B menor }\end{array}$ & $2: 02$ & \{O lamento do Pastor\} \\
\hline 6.6 & $\begin{array}{l}\text { Allegro non } \\
\text { troppo } \\
\text { E maior }\end{array}$ & $2: 08$ & \{Canção de ninar\} \\
\hline $7.1(1843-45)$ & $\begin{array}{l}\text { Andante } \\
\text { espressivo }\end{array}$ & $2: 27$ & $\{$ Devaneio $\}$ \\
\hline
\end{tabular}

${ }^{15}$ Nome presente em alguns autógrafos de Mendelssohn, ainda segundo TODD, 1979. p. 245.

${ }^{16}$ Em virtude das repetições de frases similares ascendentes e descendentes, criando uma sensação de circularidade. V. TODD, 2003, p. 491. 


\begin{tabular}{|c|c|c|c|}
\hline Opus 85 & F Maior & & \\
\hline 7.2 & $\begin{array}{l}\text { Allegro agitato } \\
\text { A menor }\end{array}$ & 1:03 & $\{O$ Adeus $\}$ \\
\hline 7.3 & $\begin{array}{l}\text { Presto } \\
\text { Eb Maior }\end{array}$ & $2: 19$ & $\{$ Delírio $\}$ \\
\hline 7.4 & $\begin{array}{l}\text { Andante sostenuto } \\
\text { D Maior }\end{array}$ & $2: 26$ & $\{$ Elegia\} \\
\hline 7.5 & $\begin{array}{l}\text { Allegretto } \\
\text { A Maior }\end{array}$ & $1: 46$ & $\{O$ Retorno\} \\
\hline 7.6 & $\begin{array}{l}\text { Allegretto con } \\
\text { moto } \\
\text { B b Maior }\end{array}$ & $2: 25$ & \{Canção do Viajante\} \\
\hline $\begin{array}{r}8.1(1842-45) \\
\text { Opus } 102\end{array}$ & $\begin{array}{l}\text { Andante un poco } \\
\text { agitato } \\
\text { E menor }\end{array}$ & $2: 47$ & $\{$ Sem teto $\}$ \\
\hline 8.2 & $\begin{array}{l}\text { Adagio } \\
\text { D major }\end{array}$ & $2: 24$ & $\{$ Um Olhar para o Passado\} \\
\hline 8.3 & $\begin{array}{l}\text { Presto } \\
\text { C Maior }\end{array}$ & $1: 33$ & $\{$ Tarantela $\}$ \\
\hline 8.4 & $\begin{array}{l}\text { Un poco agitato, } \\
\text { ma andante } \\
\text { G menor }\end{array}$ & $2: 21$ & $\{$ Os Gemidos do Vento $\}$ \\
\hline 8.5 & Allegro vivace & 1:08 & $\{$ Kinderstück (Peça infantil)\} \\
\hline
\end{tabular}




\begin{tabular}{|l|l|l|l|}
\hline & A major & & \\
\hline 8.6 & $\begin{array}{l}\text { Andante } \\
\text { C Maior }\end{array}$ & $1: 40$ & $\{$ Crença $\}$ \\
\hline
\end{tabular}

Como se pode notar, cada um dos livros de canções articula peças de variados andamentos (Tempi), tonalidades e durações. Temos uma combinação de peças mais curtas e outras mais longas. E, disto, seguem-se também peças em tonalidade maior e menor, o que, na tradição musical diatônica, apontava para estratégias de respostas emocionais - tonalidades maiores projetando mais alegria, extroversão, e as menores, tristeza, introversão ${ }^{17}$

Essa diversidade entre as peças foi desenvolvida na organização do primeiro livro e serviu de modelo para os livros posteriores ${ }^{18}$. Assim, temos um duplo movimento que intercruza a construção da série em conjuntos de seis por oito vezes, com a divisão interna de cada série em uma variação de peças ou 'capítulos' a partir de certos parâmetros: maior/menor, mais calmo/mais agitado, mais curto/ mais longo.

Dessa forma, a sucessão horizontal-cronológica das publicações manifesta a busca de uma coesão do livro por meio da distribuição das peças entre seus parâmetros de caracterização. Cada publicação é uma atualização

\footnotetext{
17 Esses parâmetros presentes na 'prática musical comum', que vai do Barroco (1600) a fim do Romantismo (1910). Expressão de Walter Piston (PISTON 1948). Para uma análise da canção artística erudita e esses parâmetros, V. KIMBALL 2006.

${ }^{18}$ Segundo TODD, 1979, p. 209-25 a ordem de elaboração não é a mesma da de publicação. Entre 1829 e 1832 foram produzidas composições das quais foram selecionadas e reelaboradas em função de sua forma final em uma publicação.
} 
do modelo, da ideia-livro. Assim, singularmente cada livro é em si uma escolha das possibilidades de materiais sonoros e afetos, e ao mesmo tempo aponta para forma mais abrangente daquilo em que se insere - o livro.

Ora, todas essas escolhas e atualizações reiteradas durante uma sucessão de publicações são ao fim explorações desse experimento interartístico levado a cabo por Mendelssohn. A matéria fluída do som reveste de uma inteligibilidade ao se integrar em uma ordem com protocolos textuais. Revertendo expectativas quanto à omissão das palavras nessa transposição da canção para uma realização instrumental, Mendelssohn, novamente em trecho de carta a Souchay, conclui:

As pessoas geralmente reclamam que a música é muito ambígua, que o que elas devem pensar quando a ouvem não é claro, enquanto que todos entendem as palavras. Mas para mim é o contrário. E não somente em relação a um discurso inteiro, mas também em palavras individuais. Elas também me parecem tão ambíguas, vagas, tão enganosas em comparação com uma música verdadeira, que enche a alma com mil coisas melhores que as palavras. Os pensamentos que me são expressos pela música que amo não são muito vagos para eu colocar em palavras, mas, ao contrário, são bem definidos. (MENDELSSOHN, 1865, p. 337, tradução nossa) ${ }^{19}$

Para ser exato, as Canções sem Palavras promovem inicialmente um intercampo de referências e trocas entre o formato livro e a tradição da canção de arte erudita. Desse modo, o resultado desse intercampo nem é apenas uma canção sem palavras, ou o mero resultado de uma extração. Ou seja, não é uma genérica antinomia entre musical e extramusical que aqui é o âmbito da questão. Simultaneamente, temos o trabalho de protocolos editoriais e composicionais, que cooperam e constituem o horizonte das

\footnotetext{
${ }^{19}$ Original em alemão: Die Leute beklagen sich gewohnlich, die Musik sei so vieldeutig; es sei so zweifelhaft was sie sich dabei zu denken hätten, und die Worte verstände doch ein jeder. Mir geht es aber gerade umgekehrt. Und nicht bloß mit ganzen Reden, auch mit einzelnen Worten; auch die scheinen mir so vieldeutig, so unbestimmt, so mißverständlich im Vergleich zu einer rechten Musik, die einem die Seele erfuillt mit tausend besseren Dingen als Worten. Das, was mir eine Musik ausspricht, die ich liebe, sind mir nicht zu unbestimmte Gedanken, um sie in Worte zu fassen, sondern zu bestimmte.
} 
decisões criativas tanto em relação à materialidade do som quanto à modelação de sua organização textual e recepcional. É o que uma análise mais detida das canções em si nos esclarece.

\section{Palavras sobre as Canções sem Palavras}

Como "canções sem palavras", o ciclo elaborado por Mendelssohn explora recursos, texturas e estilos da arte da canção erudita ${ }^{20}$. Temos uma transposição da situação performativa da canção para um pianista solo e as decorrentes e novas ações para que a transposição se efetive. Inicialmente, a dualidade física e funcional entre o canto do(s) cantor(es) e o trabalho não vocal do acompanhamento, que antes era realizado por diferentes agentes, agora funde-se em uma figura só. $\mathrm{Na}$ verdade, o desaparecimento da dualidade física e funcional dos performers acarreta a sobreposição, e não a eliminação de atos: a linha vocal melódica do cantor é incorporada dentro da atividade do performer instrumental.

As Canções sem palavras também se valem da forma tripartite do Lied: uma exposição (A), uma seção medial contrastante (B), e uma recapitulação (A) ${ }^{21}$. Ou seja, em uma tradução performativa, o início do contato entre o performer e a audiência; a exploração de materiais apresentados, demonstrando as habilidades da composição/performance; e desligamento do contato entre performer e audiência ${ }^{22}$. Dessa forma, aquilo que é um livro, uma escrita, é também uma escrita performativamente orientada, uma escrita de atos performativos, uma fenomenologia de uma situação performativa. Seus modos de começar, expandir e concluir são expostos, são audíveis. No caso da forma ABA, a seção inicial da canção apresenta tanto o

\footnotetext{
${ }^{20}$ Fato notado por Franz Bendel em 1845 (BENDEL, 2014, p.337).

${ }^{21}$ Sigo nessa discussão em ABARCA 2016, e SCHEIDELER 2015.

${ }^{22}$ Analisei tal correlação entre forma e performance na fuga em MOTA 2005.
} 
material musical (melodia e acompanhamento) quanto o pathos (caráter da música, afetos) que serão desenvolvidos, variados na seção medial; e, finalmente, temos o retorno do material apresentado no início, em jogo entre memória e saturação.

Como exemplo, temos a canção n.3 no primeiro livro, popularmente chamada de Jägerlied, Hunting Song, La chasse, (Canção de caça). A seção de abertura tem cinco compassos, nos quais se apresentam diversos elementos que contextualizam os atos do performer e da audiência ${ }^{23}$ :

\section{Figura 2: Abertura de Jägerlied}

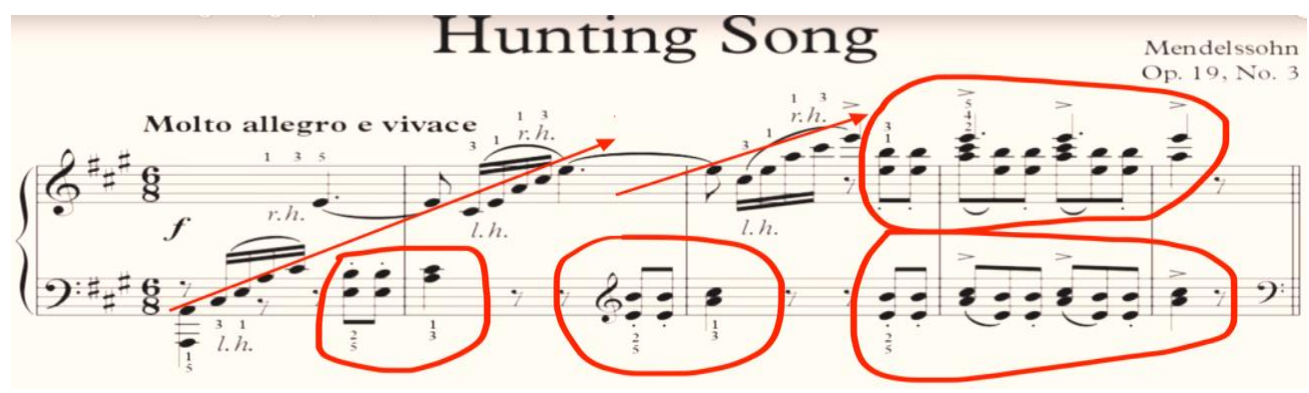

Fonte: Domínio Público.

A pequena seção inicial de 5 compassos, em um andamento bem vívido (156-176 bpm), apresenta um material sonoro empregado na tradição das fanfarras de caça: em 6/8, as trompas de caça manifestavam a celebração dos corajosos e confiantes homens nos sucessivos arpejos ascendentes na clave de sol (setas), enquanto que lhe seguem os cavalos em notas em staccato (círculos) $^{24}$. Com as duas mãos, o pianista cavalga no teclado do piano e chama seus camaradas. Essa é a breve seção A da peça.

\footnotetext{
${ }^{23}$ Para ouvir a música e ver a partitura, indico os seguintes links: https://www.youtube.com/watch?v=9zdtGEakjXk , e https://www.youtube.com/watch?v=9zdtGEakjXk ${ }^{24}$ Sobre a topicalização da caça em obras musicais, v. MONELLE, 2006, p. 35-112.
} 
Para compreender o recurso de divisão multissetorial, veja o começo da peça que fecha o primeiro livro das Canções sem palavras:

Figura 3: Abertura da Canção do Gondoleiro de Veneza.

Venetianisches Gondellied.

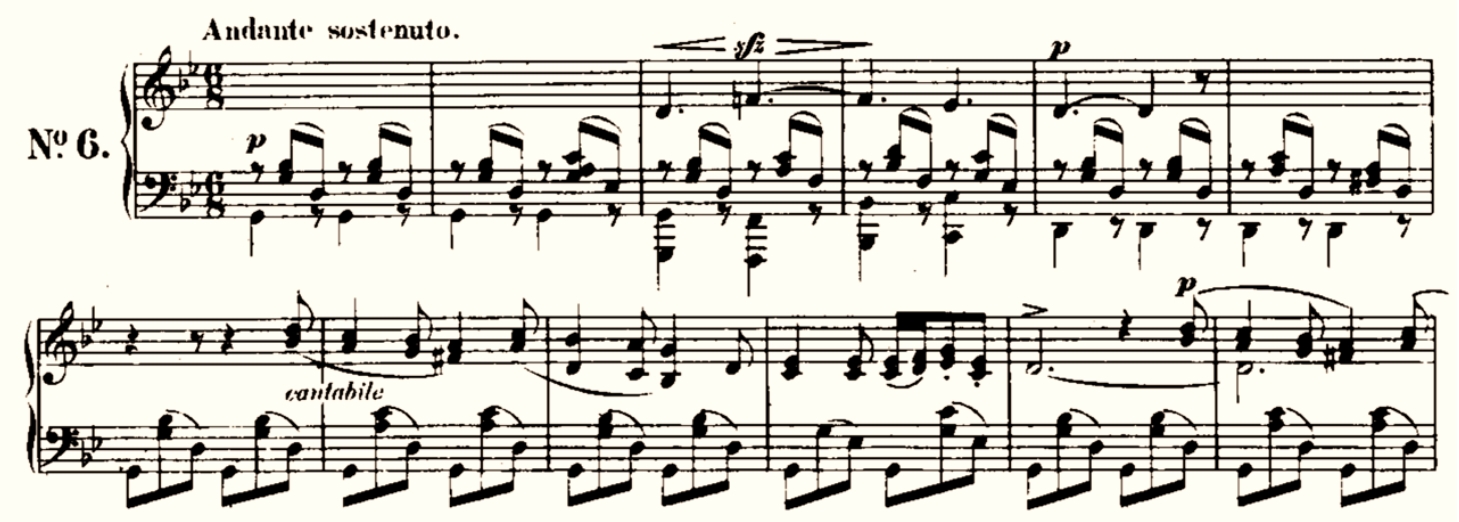

Fonte: Domínio Público

Diferentemente da obra anterior, temos um título para nos guiar: Canção do Gondoleiro de Veneza. Na mão esquerda temos arpejos interrompidos, quebrados, como o movimento das águas provocado pelos golpes do remo e da própria gôndola. No compasso três a mão direita inicia uma melodia também em vai-e-vem. No detalhe do desenho melódico, vemos que é a base harmônica que será o material para a melodia: 
Figura 4: Detalhe Canção do Gondoleiro de Veneza.
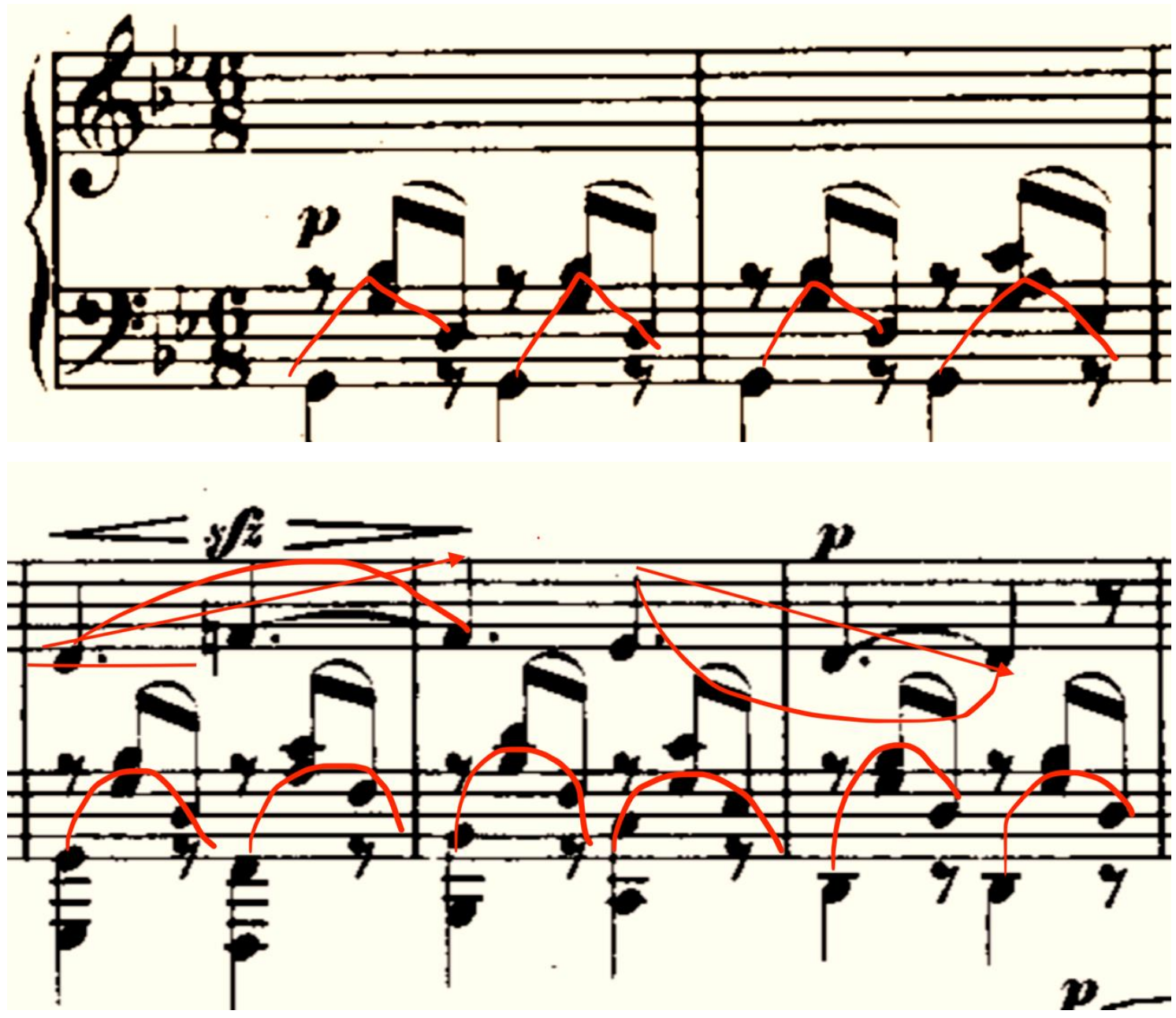

Fonte: Domínio Público

Assim, temos desenhos que se sobrepõem como ondas sobre ondas. A partitura transforma em uma analítica do acontecimento que é reinterpretado não apenas pelo som: havia toda uma modelização da figura do gondoleiro e de Veneza no imaginário da época. Mendelssohn havia viajado em 1830 para a Itália e então Veneza. Em carta de 10 de outubro 1830 ele escreve de Veneza: “Itália finalmente! E o que considero toda a minha vida como a maior felicidade possível agora começou e estou me deliciando 
com isso. Das ist Italien! Und was ich mir als höchste Lebensfreude, seit ich denken kann, gedacht habe, das ist nun angefangen, und ich genieße es (MENDELSSOHN,1862, p. 26)".

Alguns anos depois, em 1842, o próprio Mendelssohn compôs um Venetianisches Gondellied (Op. 57, n.5), agora usando versos traduzidos do poeta inglês Thomas Moore (1779-1852), produzindo uma verdadeira “Canção com palavras (Lied mit Worten)"25:

\title{
Venetianisches Gondellied / Canção do Gondoleiro Veneziano
}

\author{
Wenn durch die Piazetta /Quando pela Piazetta \\ Die Abendluft weht, /o ar da noite estiver soprando \\ Dann weißt du, Ninetta, /então você saberá, Ninetta, \\ Wer wartend hier steht. / quem está te esperando. \\ Du weißt, wer trotz Schleier/ Você sabe, apesar do véu \\ Und Maske dich kennt,/ e da máscara, quem te conhece. \\ Du weisst, wie die Sehnsucht/ Você sabe como a saudade \\ Im Herzen mir brennt./ dentro do meu coração queima. \\ Ein Schifferkleid trag' ich / Uma roupa de marinheiro vou vestir \\ Zur selbigen Zeit,/ naquele exato tempo \\ Und zitternd dir sag' ich:/ e tremendo vou dizer: \\ „Das Boot ist bereit!/ “ O barco está pronto! \\ O, komm'! jetzt, wo Lunen/ Ah, Vem! Agora, enquanto a Lua \\ Noch Wolken umziehn, /ainda está cercada de nuvens, \\ Laß durch die Lagunen,/ vamos, através das águas, \\ Geliebte uns fliehn!minha querida, fugir juntos!"
}

Outra exploração de topoi musicais é a canção do livro 5, Op. 62, n.3, relacionada a uma marcha fúnebre ${ }^{26}$. Há uma longa tradição músicoperformativa dessa modalidade de cortejo dramático-musical, como bem o demonstram as cenas de lamento na dramaturgia ateniense antiga, e os exemplos mais imediatos de Beethoven (1770-1827), Berlioz (1803-1869),

\footnotetext{
${ }^{25}$ V. TODD, 2012, p. 197-198.

${ }^{26}$ EPPSTEIN 1973; HILFIGER, 1992.
} 
Chopin (1810-1849), entre outros ${ }^{27}$. A música para este tipo de situação relaciona-se com movimento contínuo dos passos dos que levam e acompanham o morto, e com as emoções suscitadas. O trecho abaixo é da primeira parte da peça:

Figura 5: Início de Trauermarsch

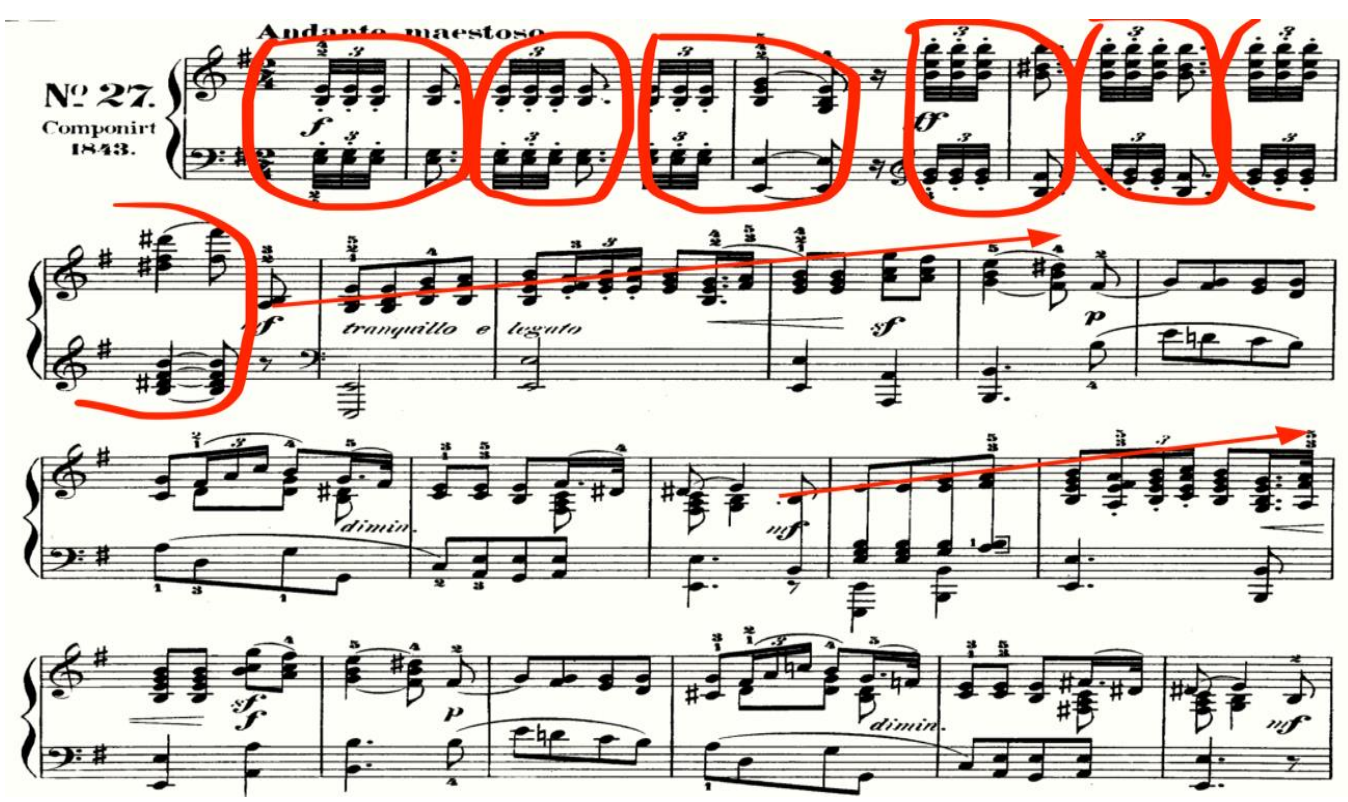

Fonte: Domínio Público

Em ritmo binário e andamento firme e contínuo (76-108 bpm), o piano começa com grupos de acordes e como sequência de passos e uma parada (círculos). Essa abertura serve de material para a melodia subsequente também em acordes (linhas). A tonalidade menor da peça associa o movimento a seu pathos. E a rubrica Andante maestoso junto com as

\footnotetext{
${ }^{27}$ DUÉ 2006, WRIGHT 1986, BURKE 1991. Gustav Mahler (1860-1911) valeu-se do material e forma dessa canção na abertura (Trauermarsch) de sua quinta sinfonia.
} 
notas em stacatto dá a expressão uma nitidez dos gestos e uma formalidade das ações.

\section{Concluindo}

Esses exemplos contribuem para que se perceba a textualidade das Canções sem Palavras. Como um livro do mundo, as peças negociam com práticas recorrentes de se transformar situações, paisagens, sensações em obras organizadas para a performance. Ao trabalhar com o imediatamente reconhecível, Mendelssohn estabelece um vínculo entre as mediações artísticas existentes e as novas peças. Há de se ter em mente que o propósito primevo dessa série de composições era prover repertório para um público massivo: pianistas que faziam a trilha sonora dos ambientes domésticos. Esse 'biscoito fino' era destinado incialmente aos intérpretes que, de suas moradas, inseriam-se em um repertório de sons e imagens que dominava as aspirações da nova sociedade ${ }^{28}$. O lirismo de as Canções sem palavras não se resume aos referentes das cenas: em uma interpretação figural desse lirismo, temos a projeção de um eu-lírico, de um sonhador em meio às paisagens, cenas e afetos aos quais multissensorialmente ele se vincula ${ }^{29}$.

Afinal, as peças são breves, com retorno de materiais sonoros, o que nos impele a considerar tais peças como experiências de uma presença em expansão, de uma atualidade que dentro dos limites do tempo, topoi, e performance prolonga-se como o espaço-tempo de uma intensa atividade imaginante ${ }^{30}$.

Assim, no lugar das ausências recursivamente declaradas em cada um dos oito livros, temos não aquilo que não é ou aquilo que não está.

\footnotetext{
${ }^{28}$ SCHMIDT,1996, p. 285-300.

${ }^{29}$ HORN, 2010.

${ }^{30}$ HATTEN, 2004; MIRKA, 2014.
} 
Ouvimos as canções, vemos os movimentos das mãos dos intérpretes, vinculamos tais materialidades a memórias e a vivências. E concebemos cada um imaginário, modelado a partir da interação com a peça.

Nesse sentido, lemos esse livro do mundo que assim se configura:

\section{Gráfico 2: Correlações entre mundo, texto, composição, performance}

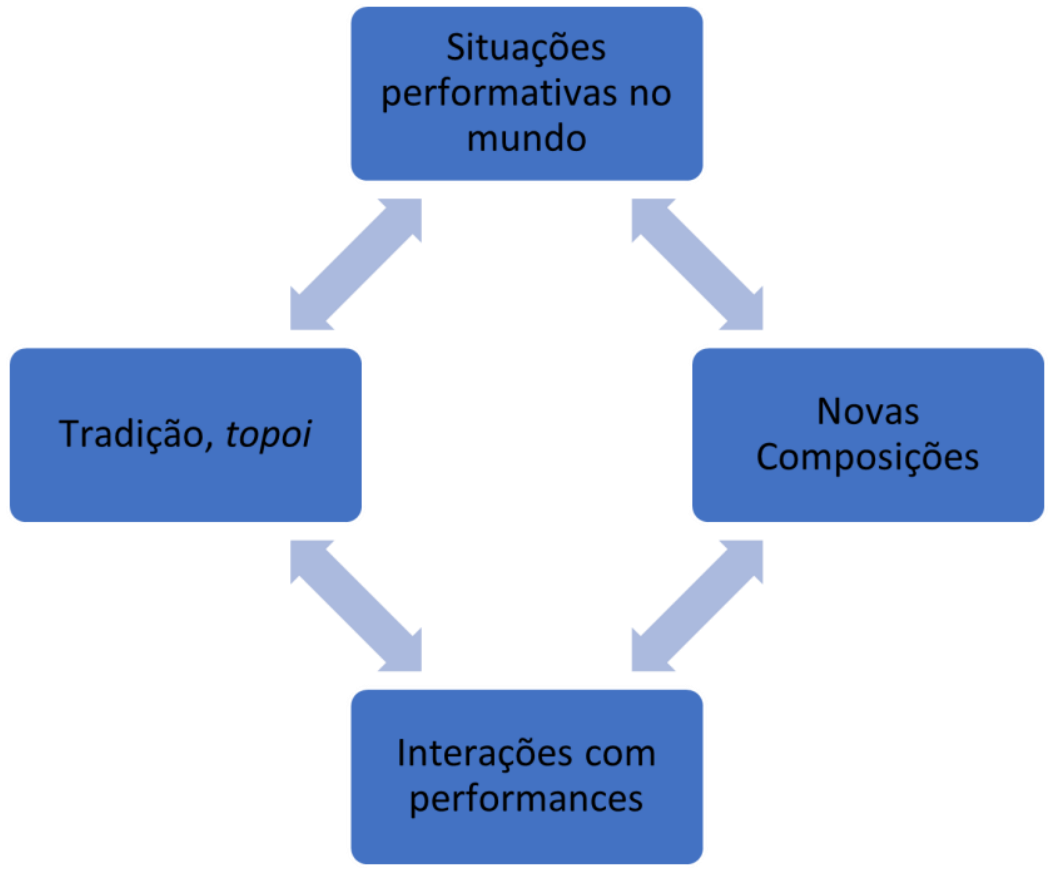

A partir desse movimento de retroalimentação e reprojeção, vemos que o sujeito inteiro é provocado a partir dos livros de Canções sem palavras: sensações, palavras, imagens, sentimentos, figuras - tudo. Ao se retirar as palavras das canções, as melodias agem como linhas, formas que são traduzidas por palavras, emoções, sutis materialidades. Como mais tarde Mallarmé pontificou, "No mundo, tudo existe para se acabar em um livro, Tout, au monde, existe pour aboutir a un livre (MALLARMÉ, 1945, p.378)." 
Logo, o experimento de Mendelssohn nos coloca diante de uma dupla provocação:

a- a nomeação da ausência de algo que está subtraído intensifica sua ausência, distorcendo-a, presentificando-a de um outro modo que sua materialidade inicial;

b- essa intensificação dialoga com o continuum recepcional, que no caso do performer e de sua audiência, é tanto mobilizado por sons e imagens visuais ${ }^{31}$.

Assim, mesmo em uma obra sonora, não há o cancelamento dos outros canais de percepção. Dessa maneira, é possível ver enquanto se ouve. E vice-versa. Ninguém fecha seus olhos em um recital, ou tranca seus ouvidos em uma obra de mímica ${ }^{32}$. Creio que essas reflexões subsidiam futuras análises e ações em projetos interartísticos e multidimensionais.

\section{Referências}

ABARCA, Faez. Chromatic Evolution of the Pre-Recapitulatory Harmony in Felix Mendelssohn's Songs Without Words. Thesis (M.A. in Music) University of Arizona, 2016.

BARTSCH, Cornelia. Das Lied ohne Worte op. 6,1 als offener Brief. In: BORCHARD Beatrix; SCHWARZ-DANUSER Monika (Orgs.) Fanny Hensel geb. Mendelssohn Bartholdy. Komponieren zwischen Geselligkeitsideal und romantischer Musikästhetik. Stuttgart: Verlag J.B. Metzler, 1999, p. 5572 .

BENDEL, Franz. Robert Schumann with Reference to MendelssohnBartholdy and the Development of Modern Music in General (1845). In: Larry Todd (Ed.). Schumann and His World. Princeton: Princeton University Press, 2014, p. 317- 337.

BURKE, Richard. The Marche funèbre from Beethoven to Mahler. 1991. Ph.D. Dissertation. City University of New York, 1991.

\footnotetext{
${ }^{31}$ Sobre a intermedialidade do ciclo, v. HUBER, 2006.

${ }^{32}$ V. MOTA, 2016.
} 
CITRON, Marcia. (Ed. e Trad). The Letters of Fanny Hensel to Felix Mendelssohn. Nova York: Pendragon Press, 1987.

COOPER, John Michael. Words without Songs? Of Texts, Titles, and Mendelssohn's Lieder ohne Worte. In: DANUSER, Hermann; PLEBUCH, Tobias (Orgs.) Musik als Text: Bericht über den Internationalen Kongress der Gesellschaft für Musikforschung. Freiburg im Breisgau: Bärenreiter, 1993, p. 341-346.

DAVERIO, John. Robert Schumann. Herald of a 'New Poetic Age'. Oxford: Oxford University Press, 1997.

DUE, Casey. The Captive Woman's Lament in Greek Tragedy. Austin: University of Texas Press, 2006.

EPPSTEIN, Hans. Lieder ohne Worte. Die Musikforschung, 26.4, p.486-490, 1973.

GIBBS, Christopher. Beyondsong: instrumental transformations and adaptations of the Lied from Schubert to Mahler. In: PARSON, James (Ed.) The Cambridge Companion to the Lied. Cambridge: Cambridge University Press, 2004, p. 223-244.

GRESHAM, Kyle. An Exploration of Graphic Archetypal Theories in Musical and Literary Analysis. Dissertação. Stephen Austin State University, 2016.

HATTEN, Robert. Interpreting Musical Gestures, Topics, and Tropes: Mozart, Beethoven, Schubert. Bloomington/Indianapolis: Indiana University Press, 2004.

HILFIGER, John. Funeral Marches, Dirges, and Wind Bands in the Nineteenth Century. Journal of Band Research, 28.1, p.1-20, 1992.

HOCHDORF, Luise. Mendelssohns Lieder ohne Worte und der Liederohne-Worte-Stil in seinen uibrigen Instrumentalwerken. Tese: Universidade de Viena, 1938. Disponível em: https://scholarworks.iu.edu/dspace/handle/2022/3115. Acesso em 20 mar 2020.

HORN, Katelyn. Daydreaming at the Keyboard: Cyclical Mediant Drifts in Nine of Mendelssohn's Lieder ohne Worte. Thesis (M.A. in Music). University of Texas at Austin, 2010.

HUBER, Annegret. Das "Lied ohne Worte" als kunstübergreifendes Experiment: Eine komparatistische Studie zur Intermedialität des Instrumentalliedes. Tutzing: Schneider, 2006 
JONES, P. Mendelssohn and his English publishers. In: TODD, Larry (Ed.) Mendelssohn Studies. Cambridge: Cambridge University Press, 1992, p. 240-255.

JOST, Christa. Mendelssohns Lieder ohne Worte. Tutzing: Hans Schneider, 1988.

KIMBALL, Carol. Song: A Guide to Art Song Style and Literature. Milwaukee: Hal Leonard Corporation, 2006.

MALLARMÉ, Stéphane. Le livre, instrument spiritua". In: Oeuvres completes. Texte établi et annoté par Henri Mondor et G. JeanAuvry. Paris: Gallimard, 1945, p. 378-382.

MENDELSSOHN, Felix. Briefe aus den Jahren 1830 bis 1847. Leipzig: Hermann Mendelssohn, $1865 . \quad$ Disponível em: https://reader.digitalesammlungen.de/de/fs1/object/display/bsb10599063_00005.html. Acesso em 20 mar 2020.

MENDELSSOHN, Felix. Reisebriefe von Felix Mendelssohn Bartholdy: aus den Jahren 1830 bis 1832. Leipzig: H. Mendelssohn, 1862.

MENDELSSOHN, Felix. Lieder Ohne Worte. Ed. Rudolf Elvers \& Ernest Herttrich. Munique: G. Henle Verlag, 2006.

MIRKA, Danuta (Ed.) The Oxford Handbook of Topic Theory. Oxford: Oxford University Press, 2014.

MONELLE, Raymond. The Musical Topic: Hunt, Military and Pastoral. Bloomington: Indiana University Press, 2006.

MOTA, Marcus. As implicações performáticas da escrita fugal: Uma leitura de A Arte da Fuga, de Bach. Tônica (UnB), 1, p. 47 - 71, 2005.

MOTA, Marcus. Música e cena: um imenso intercampo de atividades e reflexões. Revista Dramaturgias 2/3, p.2-6, 2016. Disponível em: https://periodicos.unb.br/index.php/dramaturgias/issue/view/733. Acesso em 20 mar 2020.

PALMER, Fiona. Vincent Novello (1781-1861): Music for the Masses. Londres: Routledge, 2006.

PHILLIPS, Nicholas. Mendelssohn's Songs without Words Revisited: Culture, Gender, Literature, and the Role of Domestic Piano Music in Victorian England. Ph.D. dissertation. University of Missouri-Kansas City, 2007.

PISTON, Walter. Harmony. Nova York: W.W. Norton, 1948. 
RATNER, Leonard. Romantic Music: Sound and Syntax. Nova York: Schirmer, 1992.

SCHEIDELER, Ullrich. Musikalische Zeitgestaltung in Mendelssohns Liedern ohne Worte. Zeitschrift der Gesellschaft für Musiktheorie 12.2, p. 223-243, 2015.

SCHMIDT, Thomas. Die ästhetischen Grundlagen der Instrumentalmusik Felix Mendelssohn Bartholdys. Stuttgart: J.B. Metzler, 1996.

SCHUMANN, Robert. Neue Zeitschrift für Musik, 50, jun 1835, n. 35. Disponível em: https://zs.thulb.unijena.de/receive/jportal_jpvolume_00057670. Acesso em 20 out 2020.

TISCHLER, Louise; TISCHLER, Hans. Mendelssohn's Style: The Songs without Words. Music Review 8, p. 256-273, 1947.

TODD, Larry. The Instrumental Music of Felix Mendelssohn Bartholdy: Selected Studies Based on Primary Sources. Ph.D. Dissertation. Yale University, 1979.

TODD, Larry. On the Visual in Mendelssohn's Music. In:

Mendelssohn Essays. New York: Routledge, 2008, p. 97-112.

TODD, Larry. Mendelssohn: A Life in Music. Oxford: Oxford University Press, 2003.

TODD, Larry. Mendelssohn's Lieder ohne Worte and the Limits of Musical Expression. In: MACE, Angela Regina; GRIMES, Nathan (Eds.). Mendelssohn Perspectives. Londres: Ashgate, 2012, p. 197-214.

TODD, Larry. Gerade das Lied wie es dasteht: On Text and Meaning in Mendelssohn's Lieder ohne Worte. In: PALISCA, Claude; BAKER, Nancy; HANNING, Barbara (Eds.). Musical Humanism and Its Legacy: Essays in Honor of Claude Palisca. Stuyvesant: Pendragon Press, 1992, p. 355-379.

TODD, Larry. The Piano Music Reformed: The Case of Felix Mendelssohn Bartholdy. In: (Ed.) Nineteenth-Century Piano Music. Londres: Routledge, 2004, p. 178-220.

WRIGHT, Elinor. The Form of Laments in Greek Tragedy. Tese, University of Pennsylvania, $1986 . \quad$ Disponível em: https://repository.upenn.edu/dissertations/AAI8614891/. Acesso em 30 mar 2020. 


\title{
Resumo
}

Na primeira metade do século XIX, o compositor alemão Felix Mendelssohn publicou uma série de peças para piano solo denominada Canções sem Palavras. A discussão sobre o experimento de Mendelssohn acarreta reflexões sobre as relações entre texto, música e artes em contato. A partir da ideia de livro como modelagem do mundo, este artigo explicita implicações estéticas e performativas deste experimento.

Palavras-chave: Felix Mendelssohn; Canções sem Palavras; Artes em Contato; Performance.

\begin{abstract}
In the first half of the 19th century, the German composer Felix Mendelssohn published a series of pieces for solo piano called Songs without Words. The discussion about Mendelssohn's experiment leads to reflections on the relationships between text, music and arts in contact. Based on the idea of a book as modeling the world, this article explains the aesthetic and performative implications of this experiment.
\end{abstract}

Keywords: Felix Mendelssohn; Songs without Words; Inter-arts; Performance. 